This is an electronic, pre-publication version of an article published in Media International Australia.

\title{
'Mornings with Radio 774: Can John Howard's Medium of Choice Enhance Public Sphere Activity?'
}

by Carolyne Lee

\section{Abstract}

This paper addresses the necessity for program-specific analysis in radio research by focussing on Jon Faine's Morning Program on ABC Radio 774 (Melbourne). After establishing the present Prime Minister's preference for radio appearances over all other types of media, I examine the extent to which Faine's particular iteration of talkback has the capacity to enhance public sphere activity, given the view that this medium is being strategically utilised by politicians to gain virtually uncontested access to listeners. My examination occurs principally through a morning's observation of Faine's program, supported by information from recordings of a constructed week of the program from the previous two months. My findings suggest that while a certain amount of 'top-down' flow of information is unavoidable, some contestation of ideas often occurs, mitigating politicians' exploitation of at least this particular program. Faine's program does, moreover, seem to give the impression of an acceptance of listeners calls on topics that affect their daily lives, even though only a small number of 'ordinary' callers are featured each day. My observations suggest this program does offer processes that enhance public sphere activity, although with some qualifications.

\section{Introduction}

It is now no longer news that the decade of the Howard government has been a period in which we have seen politicians make increasing use of radio. Indeed, there is a view that there has been 'strategic utilisation of talkback radio by politicians over mainstream news 
media...' (Ward, 2002: 21) John Howard, in particular, uses radio appearances more than any of his predecessors, favouring this medium for communicating with the public, mainly -it has been suggested - because it enables him to bypass tough questioning by the Press Gallery. This may well be a factor, since it is true that radio talk show hosts are generally 'not experts on government policy', as Jon Faine (2005b), host of the ABC Radio 774 Morning show, admits. Faine believes, however, that 'listeners prefer to hear the politicians talk to non-experts' (Faine, 2005b).

Whether or not this is the case, as Ward (2002: 24) has shown, the 'strategy of exploiting talkback radio to gain unfiltered access to voters worked well' for the Liberals first during the 1996 election campaign; and Howard has continued with it ever since. A brief categorisation of John Howard's 2006 interviews alone shows that radio is clearly his preferred medium, almost always significantly outnumbering television, as well as outnumbering 'doorstops' in the six months of $2006 .^{1}$

Most of these appearances are on talk or talkback radion, reflecting a situation in which radio programs that include talkback segments have become 'the preferred organ for national and state leaders to sell policies and ideas, [and] to get voter feedback...' (Faine, 2005a: 169)). This preference is, of course, because of talkback radio's reach: between 100,000 and 200,000 voters can be listening 'at any instant in a Sydney or Melbourne major interview' (Faine, 2005a: 179), a phenomenon that demonstrates radio's emergence as the medium of choice in the way many of us access news. This popularity is contrary to previous predictions of radio's demise, and may be due to the ease with which radio can be consumed while the listener is 
simultaneously engaged in other activities, such as commuting, working, or walking. It may also be due to its unique participatory function: its ability to provide an opportunity for listeners to feel they can 'have their say or exercise their democratic rights...' (Turner et al, 2006: 109). And also, while of course depending very much on the particular program and the host, there is quite simply - at least in one talk radio host's view - the capacity for talkback radio to provide to a far greater extent than television, a "contest of ideas" (Faine, 2005a: 171).

If Faine's assertion is correct, talkback radio - or at least his particular brand of it - would seem to be capable of contributing to the health of the democratic public sphere in $21^{\text {st }}$ century Australia. But how does this capacity square with Ward's arguments, quoted above, of the 'strategic utilisation' of the medium by politicians, of their 'exploitation' of it to gain 'unfiltered access to voters'? Such a view, of exploitation by elites, suggests that radio, despite its talkback segments, facilitates a 'top down' flow of communication; if this is the case, the effect would see a bolstering of existing terms of power, rather than an 'enhancing [of] the sorts of practices necessary for the making of democratic citizens... [practices that require] the articulation of interests from below as well as above' (Kane, 1998: 154). This conundrum is surely one of abiding concern to anyone with an interest in talkback radio, and will constitute the focus of this paper.

\section{From 'strategic utilisation' to 'critical engagement':} researching talkback radio 
In research in this field, the terms 'talk radio' and 'talkback' are often used interchangeably, although Jon Faine argues for a distinction along the following lines: 'Talk radio involves interviews with guests. Talkback requires the host - with or without a guest - to interact with callers over the phone' (Faine, 2005a: 173). Faine's program encompasses both aspects. Ward, on the other hand, uses the term 'talkback' in a wider sense: Talkback radio, he says, 'mixes calls from listeners, commentary on public affairs, pre-arranged interviews and newsbreaks...' (Ward, 2002: 21). For the purposes of this paper, I will use the term 'talkback radio' to describe any radio program that includes segments when listeners can ring in to talk to either the host, or to one of the interviewees (such programs will of course include some or many interviews with guests in which callers cannot participate).

The contestation surrounding the very term of talkback may reflect the historical lack of research in the area of Australian talk/talkback radio, although in the last few years such research has started to burgeon. Turner et al (2006: 107) cite the main 'pioneers' in this area (a list that includes Adams and Burton, Cook, Pearson and Potts, Mickler, and Ward), but add the rider that 'for the most part...those researching talkback radio are still seeking the analysis, data or arguments that might help them to better understand the kind of role it plays both within the mediascape and within the community at large' (Turner et al, 2006: 108). My own research is an intervention in the second category, because there still does not seem to have been 'much in the way of academic interest or analysis' (Turner et al, 2006: 107) in the relationship between talkback and processes that might enhance civic life in the Australian democratic public sphere. The participation of talkback radio callers, though, and the topics canvassed, form the focus of a paper giving the 'early results from an ARC-funded 
project on the content, audience and influence of Australian talkback radio' by Turner et al (2006: 107). The findings from this study are beginning to 'narrow down the kinds of questions we need to ask as we move towards more sophisticated analysis of this media form [given its position as] structurally embedded in the political process' (Turner et al, 2006: 107).

Until lately, then, the majority of studies into talk radio have been American, although Australian research has nevertheless included significant and groundbreaking work, such as Turner's 2001 study of the infamous Sydney talkback radio hosts' (John Laws and Alan Jones) 'Cash for Comment' scandal, an incident that served as a prime example of how 'political participation [is] restricted by those who [have] access to influencing media content' (Turner, 2001: 356). Another important Australian study in the same year, by Ward, quoted at the start of this paper, charted both the rise, and the rise in respectability, of talkback radio, and the increasing use being made of it by politicians (Ward, 2001). Whilst Ward's research would tend to demonstrate the model of the 'top-down' flow of communication, as I mentioned earlier, recent studies suggest the actual practice of talkback radio is more complex. As Turner explains, drawing on Tebbutt's research, this medium has also provided listeners with a significant break from hearing the voices of 'experts', and 'notable people', and has given voice to women and other marginalised groups (Turner, 2005). As Herbst has shown, talkback programs can 'provide an excellent, unstructured outlet for public discourse. ...[and] let callers (those who can get through) express themselves in their own words-sometimes at great length' (Herbst 1995: 270). 
It would seem, then, that talkback radio provides, at least to some extent, a unique space viable for civic society or public sphere activity (Kane, 1998: 154) in the absence of any such space elsewhere, a point noted by Turner in his suggestion that Australian talkback radio provides opportunities to 'contest, reconstruct and redefine existing terms and relations of power in the media through direct critical engagement' (Turner, 2001: 356). A crucial result of such 'critical engagement' might well be increased political participation, and a link between this participation and the activity of listening to talkback radio has been at least partially demonstrated in several (American) studies, such as those by Barker (1998 and 2002), Bennett (2001), Hofstetter and Gianos (1997), Hofstetter (1998), and Page and Tannenbaum (1996). Significantly, Barker, in his research into the Limbaugh program (a talk show in the US, broadcast from more than 660 stations), and into 'the extent to which listening to it related to participation in [elections]' (Barker, 1998: 262), labelled such shows under the rubric of 'political talk radio'.

In my current research - in which I closely examine Jon Faine's Morning show - I do not specifically make use of the term 'political talk radio', although I do view Faine's program as having a great deal to do with 'politics' in both the wide and narrow sense of the word. Of course, since the $\mathrm{ABC}$ is the public broadcaster, both Faine and his producers need to ensure they do not reveal any political partisanship, or anything that could leave them open to charges of ideological bias (impossible though it is to ever avoid such charges); nevertheless, such constraints do ensure that Faine's program could be described as 'moderate' rather than 'radical' or 'conservative'. 
Be that as it may, the link between talkback listening and political mobilization is problematic because increased political participation does not preclude outright misinformation obtained as a result of listening to talkback, as demonstrated by research into levels of misinformation in public affairs knowledge possessed by listeners to talkback radio, revealed in studies by Barker (2002), Bennett (2001), and Hofstetter (1999). Another study, of listeners to both moderate and conservative talkback radio programs, found that although political talk radio 'has been associated with increased general political participation... and awareness of issues...' (Hofstetter and Barker, 1999: 353), this effect is not universal: listeners to conservative talk radio were found to be more misinformed (than were other programs' listeners who were studied) about ideologically charged matters and about political facts. This study also found that:

'Somewhat surprisingly, the more one listens to moderate talk, the less misinformed one tends to be regarding these matters...[although] these findings do not mean that moderate talk radio programming necessarily does a better job than conservative talk programming at providing listeners with accurate information. Those inclined to listen to moderate programming may be more fair-minded than conservative talk listeners, something that the shows themselves cannot control' (Hofstetter and Barker, 1999: 353).

\section{Methodology}


As I flagged earlier in this paper, there seems to be some inherent tension between, on the one hand, the 'top down' flow of information that would appear to feature inescapably in a medium as favoured by the powerful as talkback has proved to be and, on the other hand, the 'contest of ideas' model of talkback, as argued by Jon Faine (and presumably by other hosts of programs of similar calibre). In the context of this tension I'm prompted to ask - what kind of roles might talkback radio play in the public sphere? This question needs to be followed immediately by another - what type of program do we mean? For talkback is not a singular formation by any means, and if research is to have any sort of analytic usefulness, we need to articulate clear 'distinctions between iterations of the format' (Turner et al 2006: 109).

As I have already mentioned, the specific iteration of talkback I have chosen to examine so far, in the current paper and in its forerunner (see Lee, 2005), is Jon Faine's Morning program on ABC Radio 774. My choice of this format was based on three main factors: first, the dire necessity for program-specific analysis in radio research; and second because Faine is an ideal case study due to his selfconsciousness about his role, often commenting reflectively on his own talkback processes (albeit usually quite glowingly!), both on-air, and also in other public or semi-public formats, such as university or public lectures, and most recently in his chapter in Robert Manne's book Do Not Disturb: Is the Media Failing Australia? (2005). The central argument of Faine's chapter in Manne, foreshadowed by its title 'Talk Radio and Democracy', is that 'while there are sometimes flaws in the 
way it is conducted, [talk radio] has become an integral part of the democratic debate...' (Faine, 2005a: 188). While few would dispute that the dialogic interaction made possible by talkback radio stimulates processes of democratic deliberation that can only enhance the civil life and the public sphere, this function will be greatly dependent upon the range of contending viewpoints that are aired.

In order to gain some preliminary sense of the range of viewpoints, for my earlier paper (Lee, 2005), which my current research extends, I conducted a week of observations of the topics aired on Faine's program, starting on Monday 11 July 2005, and narrowed my focus to a case study of a particularly important topic - euthanasia - first raised by one caller on that day, a terminally-ill Victorian man named Steve Guest who rang to make a plea for euthanasia to be legalised. Focussing on this case study, I showed how Guest's initial phone call 'was to have a dialogic effect that spread out in ripples across public life in Melbourne for weeks to come' (Lee, 2005: 41), strongly stimulating processes of deliberation about euthanasia in the wider community.

I argued at the time, and still do, that while it's true that all citizens cannot be personally involved in deliberation and dialogue, we can listen to the dialogic exchanges of others, and use these experiences to form our own judgments. But for this to occur, people need not only the rhetorical space of talkback radio, but also the acceptance to raise topics that affect their lives. From the point of view of 
the listener, it certainly sounds as if Jon Faine's program provides such acceptance. This, then, was my third reason for choosing his program as my object of study - but I wanted to test my assumption by observing the processes operating on the callers-in, and to discover more about how Faine chooses his topics, interviewees and callers.

Before conducting my observation, in order to add to my specific knowledge of Faine's recent program content, I assembled a 'constructed week' of his program. I did this by recording, over a five-week period in July and August 2005, editions from five different weekdays of the program, broadcast from 8.30 - 12 noon every weekday on Melbourne Radio Station 774 (that is, I ended up with a set of five Monday to Friday programs, each day taken from different, consecutive week). I intended this to complement my observations from September 192005 when I sat in Faine's producers' studio from 8.30 am through to 12 noon, and observed through the large plate-glass panel separating the two studios as Faine conducted his entire program for the morning. My objective here was to observe, record, and examine the practices, by Faine and by his producers, of structuring the content of the whole program, of dealing with callers, of selecting topics, and of conducting both interviews and the actual talkback discussions.

I followed my morning of observation by interviewing Jon Faine at the conclusion of his program. For my questions I drew on, and often problematised, 
assertions Faine had made in his chapter in Robert Manne's book (Manne, 2005), as well as on air during many of his shows.

\section{'Giving you the chance to be heard' (unless you're at the end of the queue)}

There's little doubt that Jon Faine and his producers fit a prodigious amount of content into each three-and-a-half hour program: the main topical issues that Faine, with the assistance of his producers, has chosen, and the talkback segment that follows this; the frequent traffic reports, hourly news, weather and sports reports; stock exchange reports; news from the local papers with an editor from Leader newspapers; the special weekly talkback sections such as the Talkback Lawyer, who answers callers' legal questions; the Open Line (a second talkback segment); and the Conversation Hour that includes a co-host and one or more guests or interviewees.

On my day of observation, September 19 2005, Faine started the program with the main feature-his own overview of the just-released book The Latham Diaries, by recently-resigned former opposition leader Mark Latham, a book that Faine said 'dished the dirt' on the political process. Although Faine always sounds as if he's talking 'off the cuff', for much of his commentary he reads from typed sheets (although I only saw this on my one day in the studio, it was corroborated by his producers). As a counterpoint, I assume, to the negative commentary that the Latham book had received, from the Prime Minister and the Leader of the 
Opposition downwards, the next segment of the program featured a phone interview with Leeanda Wilton, the sister of the late MP Greg Wilton, who had committed suicide five years earlier. Ms Wilton stated that Latham's criticisms of Kim Beazley (in his book) for not contacting or supporting her brother in the lead-up to his suicide were true. It was Latham, she claimed, who had offered support to her brother and her family.

The inclusion of this call highlights a number of issues: Ms Wilton, a person with close connection to the political 'elite', if not a member herself, rang and offered the phone interview, according to the producers. Because she was quite explicitly criticising Beazley, one of Faine's two producers called Beazley's office to give him right of reply: 'I've got Beazley's office on [line] 1360...' Beazley did not, however, on this occasion respond to the invitation, at least not during this program. One person who did respond, after hearing the Wilton call, was a psychiatrist, who then rang to talk to Faine about suicide. This is not a segment of the program that generally includes 'talkback', but the producers agreed to let this caller through (a move approved by Faine), and put him on hold until the Wilton interview finished, at which time the psychiatrist gave a professional view of the factors leading to suicide in general. These first two callers, Wilton and the psychiatrist, could be termed 'talkback' callers, since both were responding to material Faine was presenting; yet at the same time they are each, to a certain extent, 'experts'. Despite the valid contributions to the topic by each of these callers, then, the rhetorical space thus far constructed on this particular morning 
could not really be described as providing 'the unstructured outlet for public discourse' that Herbst (1995: 270) argues talkback programs are capable of doing.

The second major feature on Faine's program of September 19 was a state issue - the contentious tolls on freeways - about which Andrew McIntosh, Shadow Attorney General was interviewed by phone. When McIntosh broke into any sort of opaque 'weasel' talk (Watson, 2003), such as 'We're striving for flexible responses...', Faine stopped him with, 'I'm sorry, I didn't understand a word of that. Could you please explain what it means?' I've heard Faine do this on many occasions to members of elite groups, whether from parliament or from business, and I would argue that it's a strategy for demystifying some of the language of elites, something that might be a useful strategy to 'help citizens obtain information to make reasoned political judgments' (Bennett, 2001: 72), something that Bennett argues is a likely function of talk radio.

After the first of the regular 'traffic reports', Faine reminded listeners of the phone number for talkback callers (1300 222774) for the first talkback segmenton the topics he had just covered - as well as reiterating the current promotional line: 'Giving you the chance to be heard.' And indeed, callers are first heard by one of the two producers, who always offer to ring the caller straight back if they are calling from a mobile, an equitable practice, since it removes from the caller the financial burden of 'holding on' for a length of time. 
The producers then ask the callers what they have rung to talk about, and they then put the callers on hold, and record their topics and link them to a specific telephone line. The calls are then put through to Faine in a certain order, probably of interest (in the producers' views), judging by the dialogue I heard between the two producers, of which the following is a sample:

'We'll take no. 6 first; she's excellent.'

'Tony from Eildon is on Line 1. He thinks Latham's book is a wake-up call.'

'Lines 3 and 5 are pretty strong, and line 2 is funny.'

Although I did not hear the producers refuse to let any callers go on to talk to Faine, sometimes a caller who had been placed towards the back of the queue (possibly due to how 'interesting' their call was thought to be) was dropped off, if Faine ran out of time in that particular talkback segment (for example: Producer to caller: 'Geraldine, I'm sorry, but we're not going to get to your call.'). This happened several times during my morning's observation. Another type of culling occurs when Faine himself cuts off a call, possibly in case it might result in legal action, or is likely to be too unsubstantiated to be credible, or perhaps because he gets a whiff of a personal vendetta by the caller against someone. For 
example, one caller, named 'Miles', said he had some 'off the record' information from a politician. Faine refused to take this call.

Although Faine had said, during a July edition of his program, that he was just a 'cipher', when I asked during my interview of him if he really believed this, he qualified it with: 'No, we're more like filters. We look at everything that's going on, assess it, get as much as possible out in the open, into the 'marketplace of ideas', so that it can be discussed. But we do make choices and decisions. We have to. Not absolutely everything can be aired.' (Faine 2005b) The concept of the 'marketplace of ideas', has been problematised, of course; for example Hofstetter et al $(1999,366)$ suggest this marketplace now 'functions more like a "supermarket of ideas", where ideas compete not so much on the basis of merit' but rather on their packaging or presentation. It would surely be impossible for this not to be a factor, I argue, given 'the enormous numbers of press releases' (Faine 2005b) Faine receives daily, and from which only one or two can be chosen: 'The fax machine is going constantly with them coming in. We use maybe one or two to generate interviews' (Faine 2005b).

A further process that impacts upon selection of callers is if Faine finishes discussing a certain topic with callers, and then moves on to a second topic, yet a caller rings in to talk about the first, the producers tell them, 'We're not taking any more calls on that at the moment, but you can ring back in an hour [for the Open Line] if you like.' The Open Line, which runs from 10.45 - 11.00 am., is the talkback session to which callers are invited to phone in on any issue of concern. The issues raised can range enormously (see Lee, 2005), and have been dubbed 
parochial and banal by some commentators (see for example, Alcorn, 2005), although as I have shown (Lee 2005), they can range from council rulings on the lengths of dog-leads through to calls for the legalisation of euthanasia.

The number of callers that can be included in The Open Line (based on my total of five recordings and my one observation) also ranges from about four through to six or eight, depending on how long each conversation takes. There are at least two significant functions of these Open Line calls. The first is that they are often able to generate topics that Faine might raise on future programs (for more on this, see Lee, 2005). During my observation, this was certainly in evidence; for example, one caller rang in to complain about telemarketing, including that done by Australian companies now employing people to call from offshore. I then heard one of the producers say to the other: "Why don't we find out the companies involved and find out who's managing this?'

The second function is that when Faine hears something that he decides sounds like unjust treatment, he will direct the caller back to the producers to take details, and will promise to 'ask questions for you.' The example of this that occurred during my observation was when a man called in to say he had been working in Thailand for the Defence Department for 17 years, and had a Thai wife and daughter; he'd now been sent back to Australia, but his wife and daughter were not allowed in. Both of these functions demonstrate a certain amount of ceding of editorial control (despite the ordering by the producers as 
calls come in), as do the diverse nature of the calls themselves, a format that Cottle (2002) has shown to offer opportunities for democratic deepening.

\section{Conclusion}

There is no doubt that this format does offer opportunities for democratic processes, although to a limited extent. The wide range and large amount of other content needed to sustain a program of this length, and for such a wide audience, means that only about half an hour of actual talkback can be fitted in each day.

Elite callers would seem to be able to garner more ready access to Faine, supporting the 'supermarket' rather than 'marketplace' of ideas concept, where packaging is an important factor. A certain amount of 'top down' flow of information, is unavoidable, then, especially when the 'elite callers' factor is coupled with the many politicians who are interviewed. However, whilst Faine is certainly not, in his own words 'an expert on government policy' (Faine, 2005b), he nevertheless often does contest the words of elites. On my day of observation there was his questioning of a meaningless statement by the Minister he interviewed, as I described above. And Faine outlined, in my interview with him, another strategy he uses: 'What we're likely to do, if we're interviewing a minister, say, is [to] wave a press release from the opposition or someone, and say, "Well, $\mathrm{X}$ says this about what you're doing, what do you say to that?"' (Faine, 2005b). 
Moreover, and quite significantly, Faine has problematised the preference of politicians for the talk radio medium, arguing:

‘Out of respect for and deference to the skills of the specialists [political journalists], surely it would be in the public interest-and would make for a more open and accountable form of politics - if the political leaders of the nation opened themselves up more regularly to chats with those who cover that patch more exclusively. After all, as well as dealing with the prime minister and federal politics, I do take calls on pet care with the talkback vet on the same morning' (Faine, 2005a: 183).

But of course, 'it is a rare radio host who says "no" to the early morning call from the prime minister's press secretary offering the nation's leader willing to talk over the issues of the day' (Faine, 2005a: 172). Still, despite this preference for radio by John Howard and many other politicians, my data suggest that Faine does ask questions that lend weight to his claim of the 'contest of ideas' function of talk radio (2005a: 171). In my view, this means that programs such as Faine's, and similar iterations, do to a certain extent mitigate what Ward sees as politicians' exploitation of talkback programs 'to gain unfiltered access to voters' Ward (2002: 24). 
So whilst the rhetorical space provided by Faine's program, and by kindred iterations, is not completely unfiltered, neither is it unstructured (because of the moderation by his producers and by Faine). And there are ostensibly reasons for this: an unstructured free-for-all could easily end up as an unsatisfying experience for listeners, destroying the very rhetorical space it seeks to create. As it stands, Faine's program certainly would certainly seem to many listeners, I argue, to be offering acceptance of 'ordinary' callers' views, thereby providing at least the potential opportunity for listeners to feel they can 'exercise their democratic rights' (Turner et al, 2006: 109); even though only a small percentage ever do call up, with only a dozen or fewer actually having 'their say' on any one day.

Nevertheless, the evidence from my detailed observation of this iteration of talkback (supported by the patterns apparent in the five recorded programs from the previous two months), suggest that it would appear to offer significant processes that enhance civic life in the Australian democratic public sphere, although there is of course potential for further enhancement. I'm aware, however, that the views of actual listeners are tantalisingly absent from this study, an area that could form a fruitful focus for further research into this particular iteration of talkback radio.

\section{References}

Adams, P. and Burton, L., 1997, Talkback: Emperors of the Airwaves, Allen \& Unwin, Sydney. 
Alcorn, Gay, The Age, 26 May 2005.

Barker, David C., 1998, ‘The Talk Radio Community: Nontraditional Social

Networks and Political Participation', Social Science Quarterly, 79, no. 2, pp.261-272.

Barker, David C., 2002, Rushed to Judgment: Talk Radio, Persuasion and American

Political Behaviour, Columbia University Press, New York.

Bennett, Stephen Earl, 2001. 'Americans' Exposure to Political Talk

Radio and Their Knowledge of Public Affairs', Journal of

Broadcasting and Electronic Media, Fall, 2001, pp.72-86.

Cook, J., 2000, ‘Dangerously Radioactive: the Plural Vocalities of

Radio Talk", in Culture and Text: Discourse and Methodology in

Social Research and Cultural Studies, eds. Alison Lee and Cate

Poynton, 2000, Allen and Unwin, Sydney, pp 59-80.

Cottle, Simon, 2002, 'Television Agora and Agoraphobia Post-September 11', in

eds. B. Zelizer and S. Allan, Journalism After September 11, Routledge, London.

Craig, G., 2004, The Media, Politics and Public Life, Allen and Unwin, Sydney.

Faine, Jon, 2005a, 'Talk Radio and Democracy', in ed., Robert Manne, Do Not Disturb: Is the Media Failing Australia?' Black Inc, Melbourne.

Faine, Jon, 2005b, Interviewed by Carolyne Lee, September 192005 at the ABC Studios, Southbank, Melbourne. 
Herbst, Susan, 1995, ‘On Electronic Public Space: Talk Shows in Theoretical Perspective', Political Communication, Vol 12, pp. 263 - 274.

Hofstetter, C. Richard, and Christopher L. Gianos, 1997, ‘Political Talk Radio: Actions Speak Louder than Words', Journal of Broadcasting and Electronic Media, 41, no. 4, pp.501-15.

Hofstetter, C. Richard, 1998, ‘Political Talk Radio, Situational Involvement and Political Mobilization', Social Science Quarterly, 79, no. 2.

Hofstetter, C. Richard, et al, 1999, 'Information and Misinformation and Political Talk Radio', Political Research Quarterly, 52, no. 2, pp.353-369.

Kane, Thomas, 1998, ‘Public Argument, Civil Society, and What Talk Radio Teaches About Rhetoric', Argumentation and Advocacy, 34, no. 3, Winter 1998, pp.154-161.

Lee, Carolyne, 2005, 'From Dog-Leads to Dying: "Moderate" Talkback as a Rhetorical Space for Democratic Processes', Radio in the World: Radio Conference 2005, E-book:

http://search.informit.com.au/browsePublication;isbn=1921166126;res=ELIBRARY

Mickler, Steve, 2004, 'Talkback Radio, Enti-Elitism and Moral Decline', Southern Review, no. 37, p.3.

Page, Benjamin I., and Tannenbaum, Jason, 1996, 'Populist Deliberation and Talk Radio', Journal of Communication, 46, no. 2, pp.33-54.

Pearson, M. and Brand, J. 2001, Sources of News, Australian Broadcasting Authority, Sydney. 
Potts, J. 1989, Radio in Australia, University of New South Wales Press, Sydney.

Turner, Graeme, 2001, 'Ethics, Entertainment, and the Tabloid: The Case of Talkback Radio in Australia', Continuum: Journal of Media and Cultural Studies, 15, no.3, pp.349-359.

Turner, Graeme, 2005, 'Some things we should know about talkback radio', Keynote Speaker's Paper at the 2005 Radio Conference, RMIT University, 11-14 July 2005.

Ward, Ian, 2002, ‘Talkback Radio, Political Communication, and Australian Politics', Australian Journal of Communication, 29, no. 1, pp.21-38.

Watson, Don, 2003, Death sentence: The Decay of Public Language, Random House Australia, Milsons Point, NSW.

\footnotetext{
${ }^{1}$ These data are to June 12 2006, counting only media appearances within Australia, and are from the list of 'Interviews 2006 from the Prime Minister, the Hon. John Howard, MP', consulted June 12 2006:

http://www.pm.gov.au/interviews/index.cfm
} 


\section{University Library}

\section{- M M N E R VA A gateway to Melbourne's research publications}

Minerva Access is the Institutional Repository of The University of Melbourne

Author/s:

LEE, CAROLYNE

Title:

Mornings with Radio 774: can John Howard's medium of choice enhance public sphere activity?

Date:

2007

Citation:

Lee, C. (2007, February). Mornings with Radio 774: can John Howard's medium of choice enhance public sphere activity? Media International Australia.

Publication Status:

Published

Persistent Link:

http://hdl.handle.net/11343/35084 